\title{
Effects of the SGLT-2 Inhibitor Canagliflozin on Adenine-Induced Chronic Kidney Disease in Rats
}

\author{
Badreldin H. Ali ${ }^{a} \quad$ Suhail Al Salam ${ }^{b} \quad$ Yousuf Al Suleimani ${ }^{a} \quad$ Mohammed Al Za'abia \\ Aly M. Abdelrahman ${ }^{a} \quad$ Mohammed Ashique $^{a} \quad$ Priyadarsini Manoja Sirin A. Adham ${ }^{c}$ \\ Christina Hartmann ${ }^{d}$ Nicole Schupp ${ }^{d}$ Abderrahim Nemmare \\ aDepartment of Pharmacology and Clinical Pharmacy, College of Medicine and Health Sciences, \\ Sultan Qaboos University, Muscat, Oman, 'bepartment of Pathology, College of Medicine and Health \\ Sciences, UAE University, Al Ain, United Arab Emirates, 'Department of Biology, College of Science, \\ Sultan Qaboos University, Muscat, Oman, IInstitute of Toxicology, Medical Faculty, University of \\ Düsseldorf, Düsseldorf, Germany, eDepartment of Physiology, College of Medicine and Health Sciences, \\ UAE University, Al Ain, United Arab Emirates
}

\section{Key Words}

Adenine • Chronic kidney disease • Rats • Canagliflozin

\begin{abstract}
Background/Aims: SGLT-2 inhibitors have been shown to be nephroprotective in diabetes. Here, we examined if one of these drugs (canagliflozin) could also ameliorate non-diabetic chronic kidney disease (CKD). Methods: CKD was induced in rats by feeding them adenine $(0.25 \%$ w/w for 35 days) and canagliflozin (10 or $25 \mathrm{mg} / \mathrm{kg}$, by gavage) was given with or without adenine. Several conventional and novel plasma and urine biomarkers and tissues morphology were used to investigate the canagliflozin effect on kidney structure and function. Results: Rats fed adenine showed the typical features of CKD that included elevation of blood pressure, decreased food intake and growth, increased water intake and urine output, decrease in creatinine clearance, and increase in urinary albumin/creatinine ratio, liver-type fatty acid binding protein, $N$-acetyl-beta-D-glucosaminidase, and plasma urea, creatinine, uric acid, calcium, indoxyl sulfate and phosphorus concentrations. Adenine also increased concentrations of several biomarkers of inflammation such as neutrophil gelatinase-associated lipocalin, interleukin-6, tumor necrosis factor alpha, clusterin, cystatin $C$ and interleukin-1 $\beta$, and decreased some oxidative biomarkers in kidney homogenate, such as superoxide dismutase, catalase, glutathione reductase, total antioxidant activity, and also urinary 8-isoprostane and urinary 8-hydroxy-2-deoxy guanosine. Adenine significantly increased the renal protein content of Nrf2, caused renal tubular necrosis and fibrosis. Given alone, canagliflozin at the two doses used did not significantly alter any of the parameters mentioned above. When
\end{abstract}




\section{Cellular Physiology Cell Physiol Biochem 2019;52:27-39 \\ \begin{tabular}{l|l|l}
\hline DOI: 10.33594/000000003 & 2019 The Author(s). Published by
\end{tabular} \\ Published online: 18 February 2019 Cell Physiol Biochem Press GmbH\&Co. KG \\ Badreldin et al.: Canagliflozin on Adenine-Induced Chronic Kidney Disease in Rats}

canagliflozin was given concomitantly with adenine, it significantly and dose-dependently ameliorated all the measured adenine-induced actions. Conclusion: Canagliflozin ameliorated adenine-induced CKD in rats, through reduction of several inflammatory and oxidative stress parameters, and other indices such as uremic toxins, and by antagonizing the increase in the renal content of the transcription factor Nrf2. The drug caused no overt or significant untoward effects, and its trial in patients with CKD may be warranted.

(C) 2019 The Author(s). Published by

Cell Physiol Biochem Press GmbH\&Co. KG

\section{Introduction}

The incidence and prevalence of the common disorder chronic kidney disease, (CKD) [also termed in its later stage chronic renal failure (CRF)], are on the increase, both in developed and developing countries, imposing a very expensive and rising demand on health-care systems already burdened by resources scarcity $[1,2]$. The disease is progressive in nature, requires involved and frequently expensive management, causes serious complications such as cardiovascular diseases, stroke, diabetes, and other diseases, and has no satisfactory treatment [3]. Therefore, there is a need for studies into the pathophysiology and mechanisms of CKD, development of new effective therapeutic strategies, and also for the search of appropriate and valid animal models of the disease. The model should simulate, as much as possible, the human kidney disease in its natural course, as well as its histological features, which could predict renal functional outcome, and responsiveness to clinically used drugs [4]. Adenine-induced CKD in rats and mice is such a model, and has recently witnessed a surge in its usage by several investigators [5-7], since its introduction by Yokozawa et al. [8].

Sodium-glucose cotransporter (SGLT)-2 inhibitors are recently-introduced antidiabetic drugs that can increase urinary glucose excretion and reduce hyperglycemia [9]. In diabetes mellitus, they are also reported to possess some additional actions such as renoprotective effects in humans and animals [10-12] and do not cause any acute renal injury in diabetic patients [13].

In the present work, our aim was to investigate the effect of treatment with one SGLT-2 inhibitor, canagliflozin, on rats with adenine-induced CKD, using several conventional and novel physiological, biochemical, immunohistochemical and histopathological methods, with a special focus on its possible actions on the anti-inflammatory and antioxidant mechanisms in adenine-induced CKD.

\section{Materials and Methods}

Animals

Wistar rats (9-10 weeks old, weighing about $250 \mathrm{~g}$ ) were kept in a room with a temperature of $22 \pm 2{ }^{\circ} \mathrm{C}$, relative humidity of about $60 \%$, with a $12 \mathrm{~h}$ light-dark cycle (lights on at 6:00). Animals were provided ad libitum with a standard pelleted chow diet containing $0.85 \%$ phosphorus, $1.12 \%$ calcium, 0.35\% magnesium, 25.3\% crude protein and 2.5 IU/g vitamin D3 (Oman Flour Mills, Muscat, Oman) and tap water.

Ethics statement

Ethical approval for conducting the work was obtained from Sultan Qaboos University (SQU) Animal Ethics Committee (SQU/AEC/2014 -16). All procedures involving animals and their care were carried out in accordance with international laws and policies (EEC Council directives 2010/63/EU, 22 September, 2010 and NIH Guide for the Care and Use of Laboratory Animals, NIH Publications, $8^{\text {th }}$ edition, 2011).

Experimental Design

Following an acclimatization period of seven days, rats $(n=36)$ were randomly divided into six equal groups, and treated for 35 consecutive days as follows: 


\section{Cellular Physiology Cell Physiol Biochem 2019;52:27-39 \\ \begin{tabular}{l|l|l}
\hline DOI: 10.33594/000000003 & (c)19 The Author(s). Published by
\end{tabular} \\ and BiOChemistry Published online: 18 February 2019 Cell Physiol Biochem Press GmbH\&Co. KG \\ Badreldin et al.: Canagliflozin on Adenine-Induced Chronic Kidney Disease in Rats}

The $1^{\text {st }}$ group (Control) continued to receive the same diet without treatment.

The $2^{\text {nd }}$ group was given adenine in the feed at a dose of $0.25 \% \mathrm{w} / \mathrm{w}$.

The $3^{\text {rd }}$ group was treated orally with canagliflozin $(10 \mathrm{mg} / \mathrm{kg} / \mathrm{day})$.

The $4^{\text {th }}$ group was treated with adenine as in the second group and canagliflozin $(10 \mathrm{mg} / \mathrm{kg} /$ day $)$.

The $5^{\text {th }}$ group was treated with canagliflozin $(25 \mathrm{mg} / \mathrm{kg} /$ day).

The $6^{\text {th }}$ group was treated with adenine as in the second group and canagliflozin $(25 \mathrm{mg} / \mathrm{kg} /$ day).

The concentration of the adenine in the feed was as used before [5], and the dosage of canagliflozin

bracketed the doses reported in the literature [14].

Canagliflozin was suspended in hydroxypropyl methylcellulose (0.5\%) and given via oral gavage.

\section{Treatments}

Rats were placed individually in metabolic cages to collect the urine voided in the last $24 \mathrm{~h}$ of the treatment period. Twenty-four hours after the end of the treatment, the rats were anesthetized with ketamine $(75 \mathrm{mg} / \mathrm{kg}$ ) and xylazine $(5 \mathrm{mg} / \mathrm{kg}$ ) intraperitoneally, and blood (about $6 \mathrm{~mL}$ ) was collected, and together with obtained urine, centrifuged at $900 \mathrm{~g}$ at $4{ }^{\circ} \mathrm{C}$ for $15 \mathrm{~min}$ to separate plasma. The plasma and urine were stored at $-80{ }^{\circ} \mathrm{C}$ pending analysis. The two kidneys were excised, blotted on filter paper and weighed. The right kidney and most of the left one was rapidly dipped in liquid nitrogen and kept frozen at $-80^{\circ} \mathrm{C}$ for conducting biochemical tests and Western blotting. A small piece of the left kidney was placed in formol-saline for subsequent histopathological and immunohistochemical processing and examination.

\section{Physiological and biochemical measurements}

The body weights, systolic and diastolic blood pressure (BP) and the pulse rate of all rats were recorded on a weekly basis during the experimental period, as described before [15].

Plasma and urine osmolality were measured by the freezing point depression method $\left(-70^{\circ} \mathrm{C}\right)$ using a Digimatic osmometer (Osmomat 3000, Gonotec GmbH, Berlin, Germany). Plasma neutrophil gelatinaseassociated lipocalin (NGAL) activity was measured by an ELISA kit obtained from Abcam (Milton, Cambridge, UK). Urinary $N$-acetyl- $\beta$-glucosaminidase (NAG) activity was measured by kits from Diazyme (Poway, CA, USA). Other plasma and urinary biochemical biomarkers of renal functions (creatinine, urea, uric acid, calcium, phosphorus and albumin), as well as glucose were measured in an automated machine (Mindray BS-120 Chemistry Analyzer, Shenzhen, China). The plasma concentrations of tumor necrosis factor-alpha (TNF- $\alpha$ ), clusterin, and cystatin C were measured by ELISA kits obtained from Thermo Scientific (Frederick, MD, USA). Interleukin-6 (IL-6) was measured by an ELISA kit from Life Technologies Corp. (Frederick, MD, USA) and interleukin-1beta (IL-1 $\beta$ ) by an ELISA kit from Bender MedSystems GmBH (Vienna, Austria). Urine Liver-type fatty acid binding protein (L-FABP) was measured by an ELISA kit from R \& D Systems (Minneapolis, MN, USA). Urinary 8-hydroxy-2'-deoxyguanosine (8-OHdG) and 8-isoprostane were measured by ELISA kits from Abcam (Milton, Cambridge, UK). The supernatants of renal homogenates were used for the measurement of catalase (CAT), glutathione reductase (GR), superoxide dismutase (SOD) and total antioxidant capacity (TAC), as described earlier [16-18]. Nuclear factor erythroid 2-related factor 2 (Nrf2) in kidney homogenate and plasma concentration of the uremic toxin indoxyl sulfate (IS) were measured by ELISA kits from BlueGene Biotech (Shanghai, China).

\section{Histopathology}

Kidneys were excised, washed with ice-cold saline, blotted with filter paper and weighed. Each kidney was casseted and fixed directly in $10 \%$ neutral formalin for $24 \mathrm{~h}$, which was followed by dehydration in increasing concentrations of ethanol, clearing with xylene and embedding in paraffin. Four- $\mu$ m sections were prepared from paraffin blocks and stained with hematoxylin and eosin (H \& E). Sirius Red staining was carried out to measure the degree of interstitial fibrosis using a standard technique. The stained sections were evaluated by the histopathologist that participates in this project using light microscopy.

\section{Evaluation of acute tubular injury}

A pathologist (SA), who was unaware of the treatment groups, carried out the microscopic scoring of the kidney sections in a blinded fashion. A score which represents measurement of extent of acute tubular injury area in the cortical and medullary tubules was assigned on a scale of $0-4$ ( 0 , no acute tubular injury; 1 , a few focal acute tubular injury areas of $\leq 25 \%$ of the kidney; 2 , acute tubular injury area was about $26-50 \%$ 


\section{Cellular Physiology Cell Physiol Biochem 2019;52:27-39 \\ \begin{tabular}{l|l|l}
\hline DOI: 10.33594/000000003 & (c)19 The Author(s). Published by
\end{tabular} \\ Published online: 18 February 2019 Cell Physiol Biochem Press GmbH\&Co. KG \\ Badreldin et al.: Canagliflozin on Adenine-Induced Chronic Kidney Disease in Rats}

of kidney; 3, acute tubular injury area was 51-75\% of kidney; 4 , nearly the entire area shows acute tubular injury 76-100\% of kidney). The extent of necrosis was measured using Image J software (NIH, MD, USA).

\section{Evaluation of interstitial fibrosis}

The proportion of red-stained fibrotic area in the cortex and medulla of each section, stained with Sirius Red, was graded semi-quantitatively (0: $\leq 5 \%, 1: 5 \%$ to $25 \%, 2: 25 \%$ to $50 \%, 3: 50 \%$ to $75 \%, 4:>75 \%$ ), as previously described by Servais et al. and Al Za'abi et al. [19, 20].

\section{Immunohistochemistry}

Detection of Nrf2 was performed on $4 \mu \mathrm{m}$ tissue slices, as described recently [18], with the sole difference that another microscope was used to take the pictures: Leica DM750 (Leica Microsystems, Wetzlar, Germany) using the 20 -fold objective lens. The area of the Nrf2 staining was assessed by ImageJ and related to the tissue area, also evaluated with ImageJ 1.51a4 (http://imagej.nih.gov/ij) [21].

Drugs and Chemicals

Adenine was bought from Sigma-Aldrich (St. Louis, MO, USA), and canagliflozin from Invokana, Janssen Pharmaceuticals, Inc. Titusville, NJ, USA. Other chemicals used were of analytical grade.

Statistical Analysis

Statistical analysis data are expressed as mean \pm SEM and were analyzed by one-way analysis of variance followed by Bonferroni's multiple comparison tests (Graphpad Prism version 5.03, San Diego, CA, USA); $P$ less than 0.05 was considered statistically significant.

\section{Results}

\section{Basic physiological data}

The general appearance of the rats with adenine-induced CKD was subjectively judged to be improved by canagliflozin treatment.

The basic physiological data of the six groups of rats in the experiment are shown in Table 1. Adenine, given alone, caused a significant reduction in body weight and food intake, and significant increases in relative kidney weight, water intake, and urine flow $(P<0.05)$. Canagliflozin, at the two doses, caused no significant changes in the measured physiological data, except that rats on the higher dose $(25 \mathrm{mg} / \mathrm{kg})$ had significantly less body weight and higher water intake than the controls. Treatment with canagliflozin, mostly dose-dependently and significantly, mitigated the adenine-induced changes in the above measured indices.

On the last day of adenine treatment, the systolic BP of rats treated with adenine alone, and with adenine plus canagliflozin was significantly higher than at the first day of treatment, and higher than that of the control rats $(P<0.05)$. Diastolic BP and pulse rates were not affected significantly by any treatment given $(P>0.1)$ [Data not shown].

\section{Renal function tests in plasma}

Table 2 shows the effects of adenine and canagliflozin, each given either alone or in combination, on renal function tests in plasma. The adenine -treated group had a significantly higher concentration of urea, creatinine, uric acid, NGAL, calcium, phosphorus and IS $(P<$ $0.05)$ than the control group. The values obtained from rats treated with the two doses of canagliflozin were not significantly different from the control values $(P>0.1)$. Treatment with canagliflozin, mostly dose-dependently and significantly, mitigated the adenine-induced changes in the measured renal function tests $(P<0.05)$.

\section{Urinary measurements}

Table 3 shows the results of some urinary kidney function tests (albumin, albumin / creatinine, creatinine clearance, NAG activity, osmolality), and some urinary oxidative stress biomarkers L-FABP, 8-OHdG and 8-isoprostane. The adenine-treated group had a significantly 
Table 1. Effect of treatment with canagliflozin (C) on some physiological parameters in rats with adenine (A)-induced chronic kidney disease (CKD). Values in the table are means \pm SEM $(n=6)$. CKD was induced by the inclusion of $\mathrm{A}$ in the feed at a concentration of $0.25 \% \mathrm{w} / \mathrm{w}$ for 35 days, and $\mathrm{C}$ was given to rats concurrently by oral gavage. On the $35^{\text {th }}$ day of treatment, the rats were placed in metabolic cages to collect urine. Different superscripts indicate significance as follows $\left(P<0.05\right.$ was considered significant): ${ }^{\mathbf{a}}$ Control vs all groups. ${ }^{\mathbf{b}}$ A vs adenine treated groups

\begin{tabular}{|c|c|c|c|c|c|c|}
\hline Parameters/Treatment & Control & A & $\begin{array}{c}\mathrm{C} \\
(10 \mathrm{mg} / \mathrm{Kg})\end{array}$ & $\begin{array}{c}\mathrm{A}+\mathrm{C} \\
(10 \mathrm{mg} / \mathrm{Kg})\end{array}$ & $\begin{array}{c}\mathrm{C} \\
(25 \mathrm{mg} / \mathrm{Kg})\end{array}$ & $\begin{array}{c}\mathrm{A}+\mathrm{C} \\
(25 \mathrm{mg} / \mathrm{Kg})\end{array}$ \\
\hline $\begin{array}{l}\text { Change in body weight } \\
(\%)\end{array}$ & $11.3 \pm 0.6$ & $-13.1 \pm 0.9 \mathrm{a}$ & $7.4 \pm 1.1$ & $-9.8 \pm 0.7^{a}$ & $5.4 \pm 0.9^{a}$ & $1.3 \pm 1.1^{\mathrm{a}, \mathrm{b}}$ \\
\hline $\begin{array}{l}\text { Relative kidney weight } \\
\text { (\%) }\end{array}$ & $0.6 \pm 0.0$ & $1.5 \pm 0.1 \mathrm{a}$ & $0.7 \pm 0.0$ & $1.4 \pm 0.1 \mathrm{a}$ & $0.7 \pm 0.0$ & $1.2 \pm 0.0 \mathrm{a}, \mathrm{b}$ \\
\hline Water intake $(\mathrm{mL})$ & $20.4 \pm 1.2$ & $74.6 \pm 1.5^{\mathrm{a}}$ & $25.0 \pm 2.3$ & $64.2 \pm 2.8^{\mathrm{a}}$ & $31.7 \pm 3.1^{\mathrm{a}}$ & $55.8 \pm 2.5^{\mathrm{a}, \mathrm{b}}$ \\
\hline Urine flow $(\mu \mathrm{L} / \mathrm{sec})$ & $0.2 \pm 0.0$ & $0.5 \pm 0.0^{\mathrm{a}}$ & $0.2 \pm 0.0$ & $0.5 \pm 0.0^{\mathrm{a}}$ & $0.2 \pm 0.0$ & $0.4 \pm 0.0^{\mathrm{a}, \mathrm{b}}$ \\
\hline Food intake (g) & $20.5 \pm 0.8$ & $14.6 \pm 0.5^{a}$ & $18.9 \pm 0.6$ & $22.0 \pm 0.9^{b}$ & $18.3 \pm 0.8$ & $21.6 \pm 0.7^{b}$ \\
\hline Feces output (g) & $8.3 \pm 0.7$ & $6.2 \pm 0.3$ & $5.9 \pm 0.3$ & $6.6 \pm 0.8$ & $6.2 \pm 0.4$ & $8.8 \pm 0.8$ \\
\hline
\end{tabular}

Table 2. Effect of treatment with canagliflozin (C) on some renal function tests in plasma of rats with adenine (A)-induced chronic kidney disease (CKD). Values in the table are means \pm SEM $(n=6)$. CKD was induced by the inclusion of $\mathrm{A}$ in the feed at a concentration of $0.25 \% \mathrm{w} / \mathrm{w}$ for 35 days, and $\mathrm{C}$ was given to rats concurrently by oral gavage. On the $35^{\text {th }}$ day of treatment, the rats were placed in metabolic cages to collect urine. NAGL: neutrophil gelatinase-associated lipocalin. Different superscripts indicate significance as follows $(P<0.05$ was considered significant): ${ }^{a}$ Control vs all groups. ${ }^{b} \mathrm{~A}$ vs adenine treated groups

\begin{tabular}{|c|c|c|c|c|c|c|}
\hline Parameters/Treatment & Control & A & $\begin{array}{c}\mathrm{C} \\
(10 \mathrm{mg} / \mathrm{Kg})\end{array}$ & $\begin{array}{c}A+C \\
(10 \mathrm{mg} / \mathrm{Kg})\end{array}$ & $\begin{array}{c}\mathrm{C} \\
(25 \mathrm{mg} / \mathrm{Kg})\end{array}$ & $\begin{array}{c}A+C \\
(25 \mathrm{mg} / \mathrm{Kg})\end{array}$ \\
\hline Urea (mmol/L) & $3.7 \pm 0.2$ & $22.0 \pm 1.4^{\mathrm{a}}$ & $4.2 \pm 0.3^{b}$ & $19.4 \pm 0.8^{a}$ & $4.6 \pm 0.3^{b}$ & $17.2 \pm 1.0^{\mathrm{a}, \mathrm{b}}$ \\
\hline Creatinine $(\mu \mathrm{mol} / \mathrm{L})$ & $17.1 \pm 1.0$ & $83.3 \pm 5.9 a$ & $20.1 \pm 1.1^{b}$ & $72.6 \pm 5.1^{\mathrm{a}}$ & $22.8 \pm 2.1^{b}$ & $64.8 \pm 4.2^{\mathrm{a}, \mathrm{b}}$ \\
\hline Uric acid $(\mu \mathrm{mol} / \mathrm{L})$ & $32.8 \pm 2.0$ & $81.5 \pm 3.4^{a}$ & $30.2 \pm 1.1^{b}$ & $69.3 \pm 3.3^{\mathrm{a}, \mathrm{b}}$ & $27.9 \pm 1.5^{b}$ & $53.7 \pm 2.6^{\mathrm{a}, \mathrm{b}}$ \\
\hline NGAL (ng/mL) & $27.7 \pm 2.1$ & $96.9 \pm 5.9 a$ & $25.1 \pm 2.0^{\mathrm{b}}$ & $79.3 \pm 6.1^{a}$ & $26.6 \pm 1.9 \mathrm{~b}$ & $68.3 \pm 4.1^{\mathrm{a}, \mathrm{b}}$ \\
\hline Calcium (mmol/L) & $0.9 \pm 0.0$ & $0.4 \pm 0.0^{\mathrm{a}}$ & $0.8 \pm 0.0^{\mathrm{b}}$ & $0.4 \pm 0.0^{\mathrm{a}}$ & $0.8 \pm 0.0^{\mathrm{b}}$ & $0.5 \pm 0.0^{\mathrm{a}}$ \\
\hline Phosphorus (mmol/L) & $0.6 \pm 0.0$ & $2.1 \pm 0.1^{\mathrm{a}}$ & $0.7 \pm 0.0^{\mathrm{b}}$ & $1.9 \pm 0.1^{\mathrm{a}}$ & $0.8 \pm 0.1^{b}$ & $1.8 \pm 0.1^{\mathrm{a}}$ \\
\hline $\begin{array}{l}\text { Indoxyl sulfate } \\
(\mu \mathrm{g} / \mathrm{mL})\end{array}$ & $0.5 \pm 0.2$ & $13.4 \pm 1.7 \mathrm{a}$ & $0.0 \pm 0.0$ & $4.4 \pm 0.4^{\mathrm{a}}$ & $0.0 \pm 0.0$ & $1.8 \pm 0.4^{\mathrm{a}}$ \\
\hline Glucose (mmol/L) & $5.5 \pm 0.3$ & $4.9 \pm 0.2$ & $5.2 \pm 0.1$ & $4.8 \pm 0.1$ & $5.3 \pm 0.1$ & $5.1 \pm 0.2$ \\
\hline
\end{tabular}




\section{Cellular Physiology Cell Physiol Biochem 2019;52:27-39

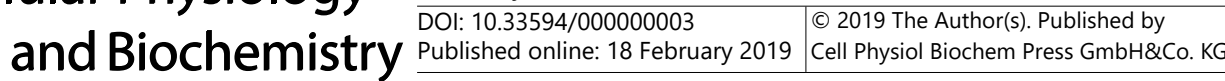

Table 3. Effect of treatment with canagliflozin (C) on some urinary constituents in rats with adenine (A)induced chronic kidney disease (CKD). Values in the table are means $\pm \operatorname{SEM}(n=6)$. CKD was induced by the inclusion of $\mathrm{A}$ in the feed at a concentration of $0.25 \%{ }^{\mathrm{w} / \mathrm{w}}$ for 35 days, and $\mathrm{C}$ was given to rats concurrently by oral gavage. On the $35^{\text {th }}$ day of treatment, the rats were placed in metabolic cages to collect urine. NAG: $N$-acetyl- $\beta$-glucosaminidase; L-FABP: Liver-type fatty acid binding protein; 8-OHDG: 8-hydroxy-2'deoxyguanosine. Different superscripts indicate significance as follows $(P<0.05$ was considered significant): ${ }^{\text {a }}$ Control vs all groups. ${ }^{\text {b A vs adenine treated groups }}$

\begin{tabular}{|c|c|c|c|c|c|c|}
\hline Parameters/Treatment & Control & A & $\mathrm{C}(10 \mathrm{mg} / \mathrm{Kg})$ & $\begin{array}{c}\mathrm{A}+\mathrm{C} \\
(10 \mathrm{mg} / \mathrm{Kg})\end{array}$ & $\mathrm{C}(25 \mathrm{mg} / \mathrm{Kg})$ & $\begin{array}{c}A+C \\
(25 \mathrm{mg} / \mathrm{Kg})\end{array}$ \\
\hline Albumin (g/L) & $3.9 \pm 0.3$ & $11.4 \pm 0.8^{a}$ & $3.0 \pm 0.2$ & $7.4 \pm 0.7 \mathrm{a}, \mathrm{b}$ & $2.2 \pm 0.2$ & $4.9 \pm 0.7 \mathrm{~b}$ \\
\hline $\begin{array}{l}\text { Albumin/creatinine } \\
\text { ratio (nmol) }\end{array}$ & $1.4 \pm 0.1$ & $26.9 \pm 2.4^{\mathrm{a}}$ & $1.1 \pm 0.1$ & $14.1 \pm 0.9 \mathrm{a}, \mathrm{b}$ & $0.7 \pm 0.1$ & $4.9 \pm 1.2^{b}$ \\
\hline $\begin{array}{l}\text { Creatinine clearance } \\
(\mathrm{mL} / \mathrm{min})\end{array}$ & $2.2 \pm 0.1$ & $0.2 \pm 0.0^{\mathrm{a}}$ & $2.0 \pm 0.1$ & $0.2 \pm 0.0^{\mathrm{a}}$ & $2.5 \pm 0.2$ & $0.6 \pm 0.1^{\mathrm{a}}$ \\
\hline NAG (IU/L) & $3.1 \pm 0.2$ & $19.2 \pm 1.2^{\mathrm{a}}$ & $3.2 \pm 0.3$ & $18.3 \pm 1.0^{a}$ & $3.5 \pm 0.3$ & $15.7 \pm 0.8^{\mathrm{a}, \mathrm{b}}$ \\
\hline $\begin{array}{l}\text { Osmolality } \\
\text { (mOsmol/Kg) }\end{array}$ & $1460.8 \pm 40.2$ & $190.3 \pm 2.7^{a}$ & $1578.7 \pm 47.3$ & $307.5 \pm 21.4^{\mathrm{a}}$ & $1658.8 \pm 70.5$ & $627.0 \pm 43.4^{\mathrm{a}, \mathrm{b}}$ \\
\hline L-FABP $(\mathrm{ng} / \mathrm{mL})$ & $0.2 \pm 0.0$ & $1.2 \pm 0.0^{\mathrm{a}}$ & $0.2 \pm 0.0$ & $0.8 \pm 0.0^{\mathrm{a}}$ & $0.2 \pm 0.0$ & $0.6 \pm 0.1^{\mathrm{a}, \mathrm{b}}$ \\
\hline 8-OHDG (ng/mL) & $121.9 \pm 11.6$ & $46.4 \pm 2.3^{\mathrm{a}}$ & $133.9 \pm 9.6$ & $55.0 \pm 4.7 \mathrm{a}$ & $140.1 \pm 7.1$ & $99.6 \pm 13.3^{a, b}$ \\
\hline 8 Isoprostane $(\mathrm{pg} / \mathrm{mL})$ & $1719.2 \pm 213.3$ & $105.0 \pm 9.4^{\mathrm{a}}$ & $2066.2 \pm 361.2$ & $433.8 \pm 98.4^{a}$ & $2568.5 \pm 385.3$ & $958.8 \pm 98.5^{\mathrm{a}, \mathrm{b}}$ \\
\hline
\end{tabular}

higher albumin, albumin-creatinine ratio, NAG and L-FABP, and significantly lower creatinine clearance, osmolality, 8-OHdG and 8-isoprostane. The values obtained from rats treated with the two doses of canagliflozin were not significantly different from the control values $(P>$ $0.1)$, except for 8-isoprostane, which was significantly higher than in the control $(P<0.05)$. Co-treatment with canagliflozin significantly and dose-dependently mitigated the actions of adenine on these indices $(P<0.05)$.

\section{Plasma cytokines and other proteins}

The plasma concentrations of IL-6, IL-1 $\beta$, TNF- $\alpha$, clusterin and cystatin are shown in Fig. 1. Canagliflozin, at the two doses, did not significantly affect the concentrations of the analytes measured $(P>0.1)$. However, adenine treatment significantly elevated them $(P<$ $0.0001)$. Concomitant treatment with canagliflozin significantly and dose-dependently mitigated the actions of adenine on these indices $(P<0.05)$.

\section{Renal antioxidants}

Fig. 2 depicts the levels of some antioxidant indices (SOD, CAT, GR, and TAC) in kidney homogenates. Adenine treatment induced significant reductions in these four antioxidants measured $(P<0.0001)$. Compared with the control, canagliflozin, at both doses, did not cause any significant change in the levels of these measurements, except for an increase in SOD activity, which was significantly increased by the higher dose of canagliflozin used $(P<$ 0.0001). Canagliflozin, at the two doses, dose-dependently ameliorated the adenine-induced action. 
Fig. 1. The expression of specific biomarkers: interleukin 6 (IL-6), interleukin 1 beta (IL$1 \beta)$, tumor necrosis factor alpha (TNF- $\alpha$ ), clusterin, and cystatin $\mathrm{C}$ in the plasma of control rats, rats treated with adenine (A), or canagliflozin (C), separately or in combination. Each column and vertical bar represent mean \pm SEM $(\mathrm{n}=6)$. Differences between the groups were assessed by oneway analysis of variance (ANOVA) followed by Bonferroni's multiple comparison test.
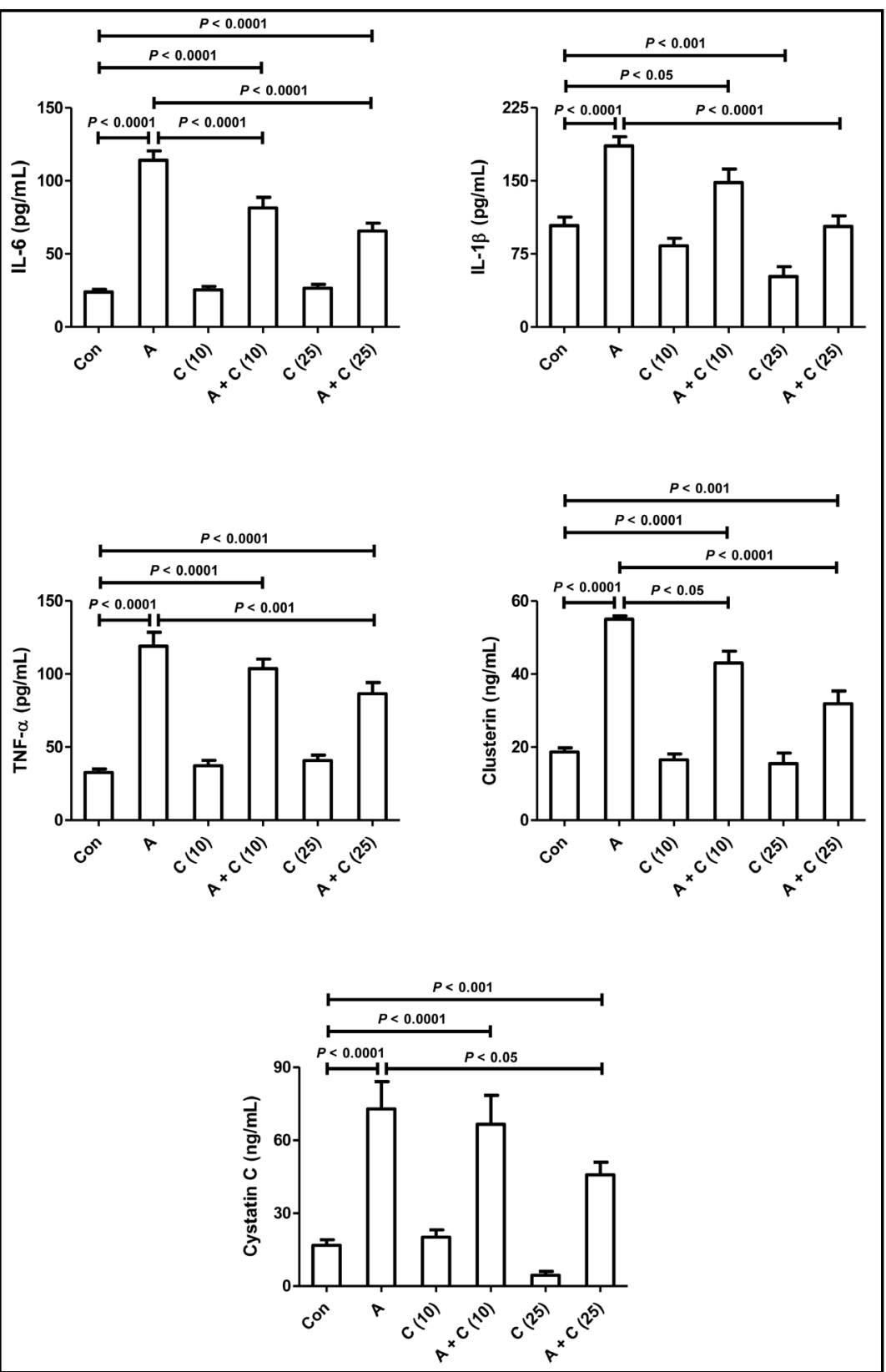

The renal content of Nrf2 was significantly increased by adenine treatment $(P<0.0001)$, while treatment with canagliflozin alone did not significantly alter it. Canagliflozin, at the two doses, dose-dependently ameliorated the adenine-induced action, and at the higher dose of canagliflozin, Nrf2 renal content was almost the same in either the presence or absence of adenine $(P>0.01)$.

\section{Histopathology}

Grossly, the kidneys from the controls and canagliflozin-treated rats appeared normal. However, the kidneys of rats fed adenine were pale and with white crystals, similar to those described before [5]. The gross appearance of the kidneys of the animals treated with adenine plus canagliflozin appeared markedly improved compared with the kidneys of rats given adenine alone. 
Fig. 2. Renal concentration or activity of superoxide dismutase (SOD), catalase (CAT), glutathione reductase (GR), total antioxidant capacity (TAC), and nuclear factor erythroid 2related factor 2 (Nrf2) in control rats, rats treated with adenine (A), or canagliflozin (C), separately or in combination. Each column and vertical bar represent mean \pm SEM $(n=6)$. Differences between the groups were assessed by one-way analysis of variance (ANOVA) followed by Bonferroni's multiple comparison test.
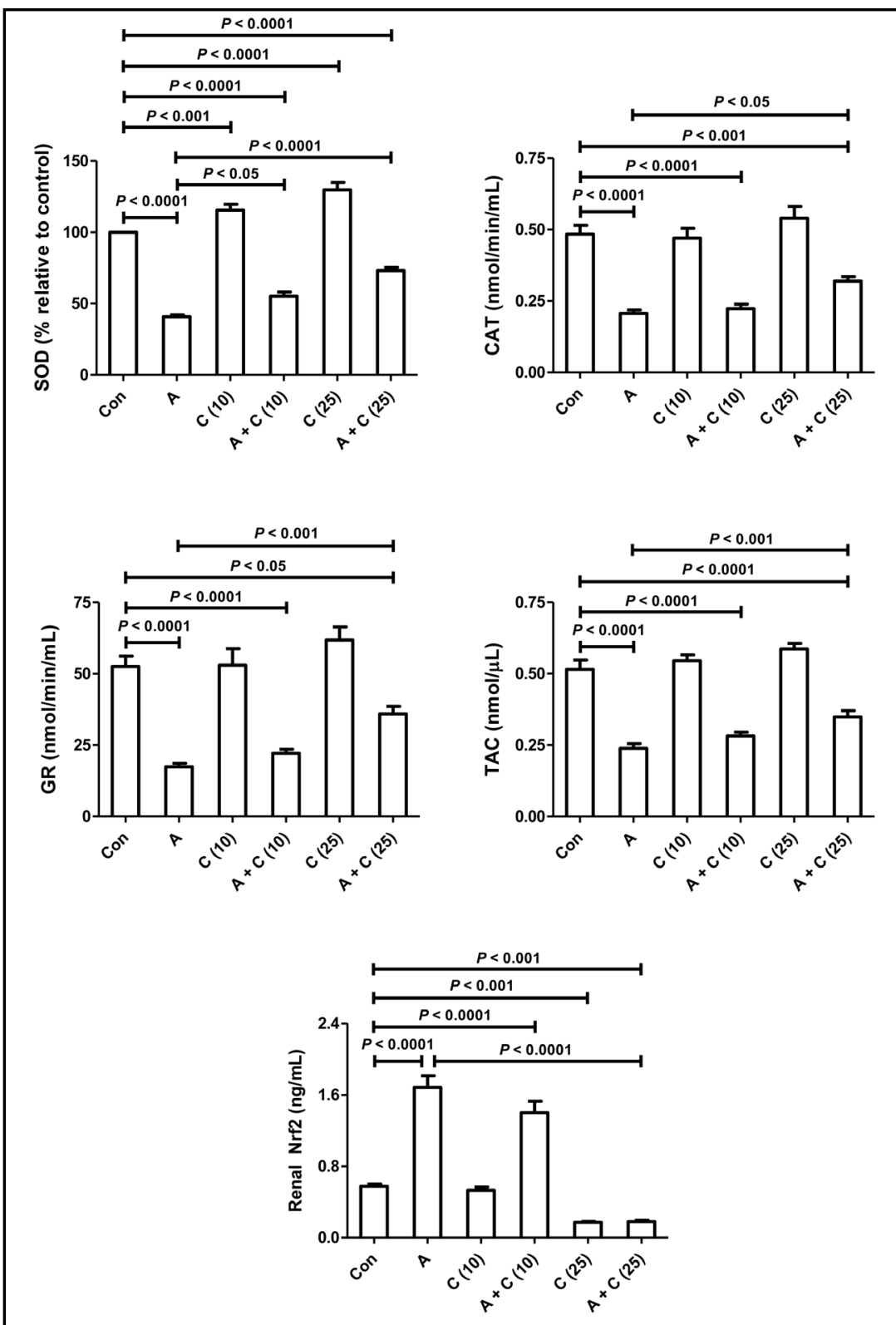

Sections stained with H\&E from the control group (Fig. 3A), and groups treated with doses of $10 \mathrm{mg}$ and $25 \mathrm{mg}$ canagliflozin (Fig. 3C and 3E, respectively) showed normal kidney architecture and histology. They were given a score of 0 for necrosis. Sections from the same groups stained with Sirius Red (Fig. 4) showed no evidence of fibrosis and were given a fibrosis score of 0 (Fig. 4A, D, and G).

Sections from the adenine- treated group revealed large areas of acute tubular injury in $61.4 \pm 4.8 \%$ of examined tissue areas (score 3 ). They also showed tubular distention with necrotic material involving tubules, loss of brush border of proximal tubules, dilatation of large number of tubules, mixed inflammatory cells infiltration of the interstitium, focal tubular atrophy (Fig. 3B), and significant interstitial fibrosis (32 $\pm 5.4 \%$, score 2$)$, as depicted in Fig. 4B and C.

The group treated with adenine and canagliflozin $(10 \mathrm{mg} / \mathrm{kg})$ showed a significant improvement in the histological appearance when compared with the group treated with adenine alone. There were foci of acute tubular injury in $33.7 \pm 5.4 \%$ of the examined tissue 


\section{Cellular Physiology Cell Physiol Biochem 2019;52:27-39

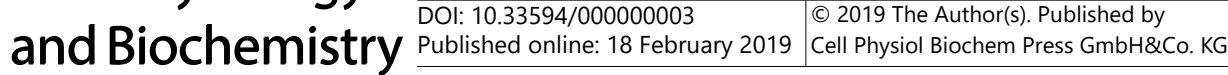

Fig. 3. Representative photographs of renal tissues sections stained with hematoxylin and eosin (H\&E) from control rats (A), and rats treated with adenine $(\mathrm{B})$, canagliflozin $10 \mathrm{mg} / \mathrm{kg}(\mathrm{C})$, canagliflozin $10 \mathrm{mg} / \mathrm{kg}+$ adenine (D), canagliflozin $25 \mathrm{mg} / \mathrm{kg}$ (E), and canagliflozin $25 \mathrm{mg} / \mathrm{kg}+$ adenine (F). No histological changes were seen in the control or the canagliflozin treated two groups. The adenine-treated group showed large areas of acute tubular injury, tubular distention with necrotic material involving tubules, loss of brush border of proximal tubules, dilatation of large number of tubules, mixed inflammatory cells infiltration of the interstitium and focal tubular atrophy. The two groups that received canagliflozin + adenine showed improvement in the histological appearance, with less dilated tubules, interstitial inflammation and atrophic tubules apoptotic cells.

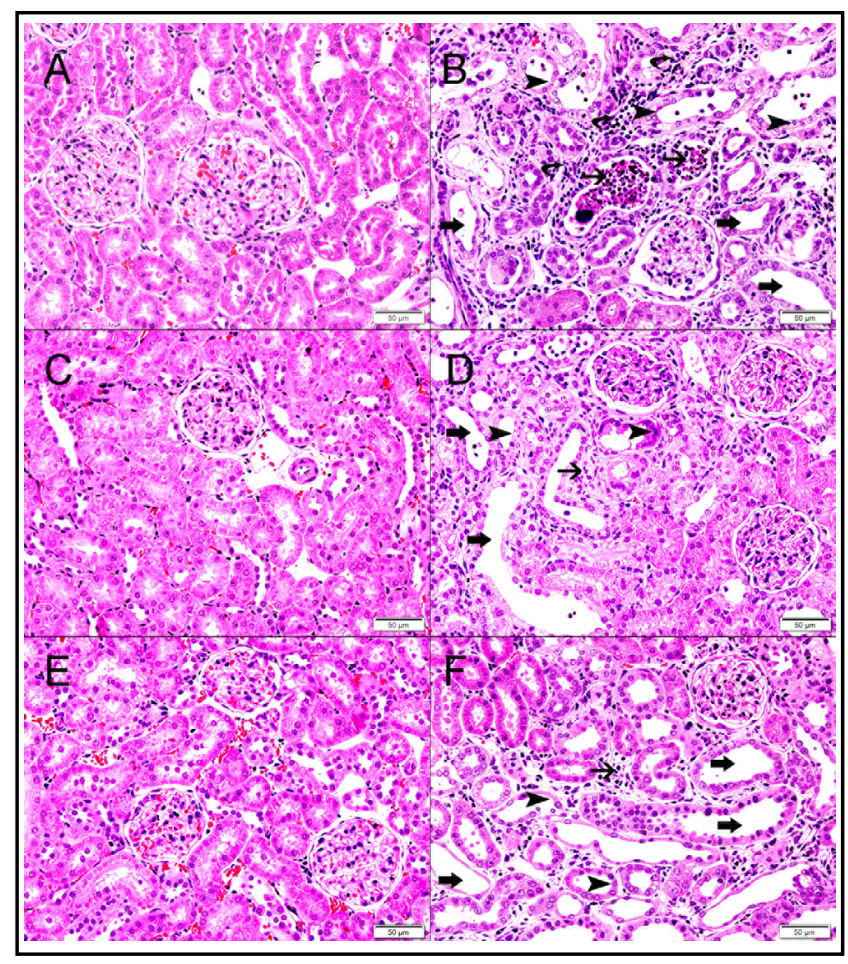

Fig. 4. Representative photographs of renal tissues sections stained with Sirus Red from control rats (A), and rats treated with adenine (B and $\mathrm{C}$ ), canagliflozin $10 \mathrm{mg} / \mathrm{kg}$ (D), canagliflozin $10 \mathrm{mg} /$ $\mathrm{kg}+$ adenine ( $\mathrm{E}$ and F), canagliflozin

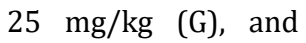
canagliflozin $25 \mathrm{mg} /$ $\mathrm{kg}+$ adenine $(\mathrm{H}$ and I). No evidence of interstitial fibrosis was seen in the control or canagliflozin groups (A, D, and G). Adenine

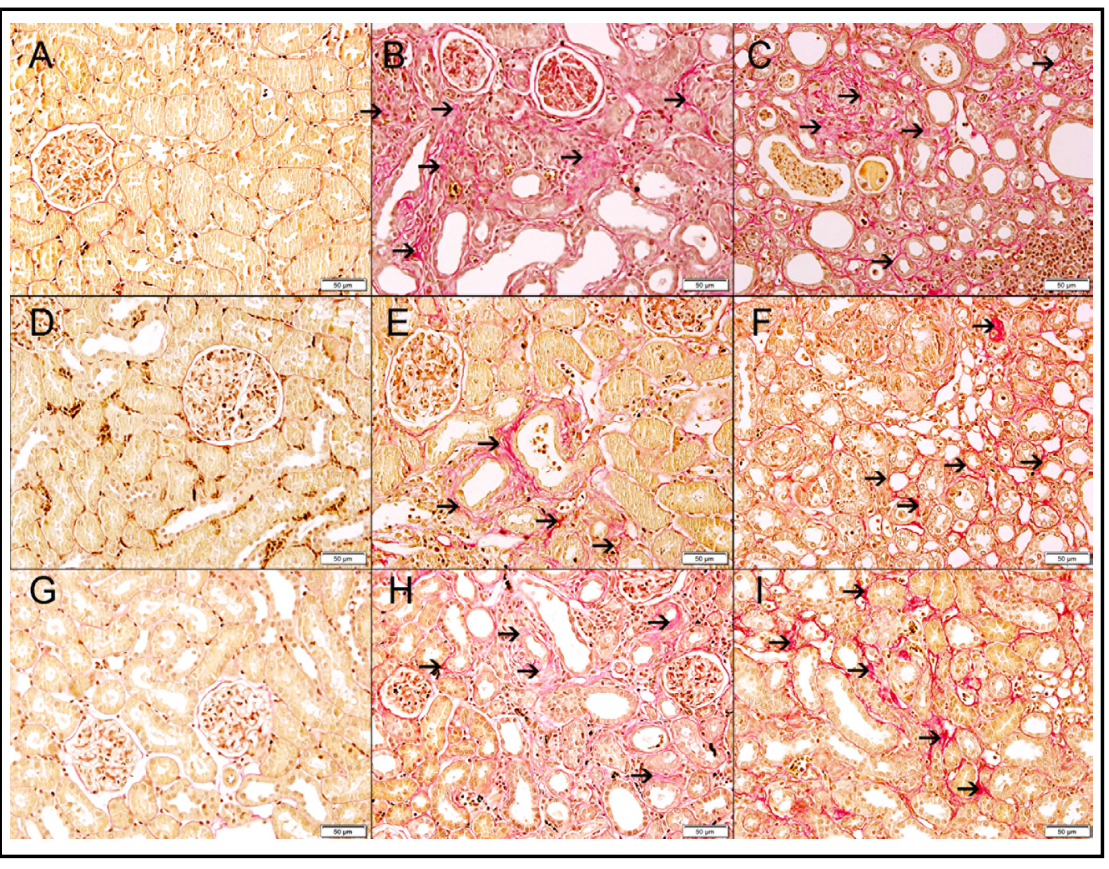
feeding induced significant interstitial fibrosis (B and C). The two groups that received canagliflozin + adenine showed significant improvement in the interstitial fibrosis (E, F, H and I).

areas (score 2). There was also less dilatation of tubules, less interstitial inflammatory cells infiltration, less tubular atrophy (Fig. 3D), and less interstitial fibrosis, amounting to $15.2 \pm$ $3.7 \%$, (score 1), as depicted in Fig. 4E and F.

The group treated with adenine and canagliflozin $(25 \mathrm{mg} / \mathrm{kg})$ showed a significant improvement in the histological appearance when compared with the group treated with 


\section{Cellular Physiology Cell Physiol Biochem 2019;52:27-39 \\ \begin{tabular}{l|l|l} 
and Biochemistry $10.33594 / 000000003$ & Published online: 18 February 2019 & Cell Physiol Biochem Press GmbH\&Co. KG \\
\hline
\end{tabular} \\ Badreldin et al.: Canagliflozin on Adenine-Induced Chronic Kidney Disease in Rats}

adenine alone. There were foci of acute tubular injury involving $31.3 \pm 3.6 \%$ of examined areas (score 2), as shown in Fig. 3F. There was also less dilatation of the tubules, less interstitial inflammatory cells infiltration, less tubular atrophy, and less interstitial fibrosis $17.3 \pm 3.4 \%$ (score 1), as depicted in Fig. $4 \mathrm{H}$ and I.

\section{Discussion}

Canagliflozin is one of the SGLT- 2 selective inhibitors that represent novel therapeutic approaches in the management of type 2 diabetes mellitus, as they act on kidneys to lower the renal threshold for glucose and enhance the urinary glucose excretion [22]. However, its possible effect on renal structure and function in CKD has not yet been elucidated.

We used here a simple, reliable and well-tested rodent model for studying various aspects of CKD, which is probably more similar to the human condition than the $5 / 6$ nephrectomy model $[7,8,23]$. Adenine administration $(0.25 \%$ in feed to rats for 35 days) induced a state of CKD characterized by worsened kidney function and chronic tubulointerstitial nephropathy and fibrosis [5].

To quantify the degree of renal damage, we have used in this work several traditional indicators such as urea and creatinine, as well as novel biomarkers in plasma and urine such as IS, NGAL, L- FABP and NAG [24], and we have shown that canagliflozin, at the two doses used, significantly improved most structural and functional features of the affected kidney. No overt adverse effects of treatment with this drug have been observed.

In this work, adenine increased the kidney weight relative to body weight, which indicates the enlargement of the kidneys. Concurrent administration of canagliflozin with adenine ameliorated this action (Table 1). The increase in the relative kidney weight and alterations in the morphology of kidney have been described previously in rats with adenine CKD $[17,18]$. The increase in the relative kidney weight in chronic diseases (such as CKD) is mostly due to TGF- $\beta$ /fibrotic response, the mitigation of which decreases the rise in kidney weight $[20,25]$. Canagliflozin treatment reduced the body weight of treated rats, when compared with the control. This reduction, seen also in humans, has been ascribed to the induction of calorie loss [10], and is unlikely to pose a serious problem to treated patients.

The mechanisms involved in the amelioration of adenine-induced CKD in rats are, most likely, multi-factorial [7]. These may include suppression of inflammation and oxidative stress, as shown experimentally in this work, using several biochemical indices in plasma and urine. It is established that oxidative stress, inflammatory reactions and apoptosis have an important influence on the pathophysiological process of uremia and its complications, especially in cardiovascular conditions [26-30], and are considered among the most important pathophysiological features in CKD. The concentration or activity of their biomarkers correlates with the severity of CKD and the status of renal function [27].

Agents that can mitigate these pathophysiological conditions can prevent, treat or retard the progression of this disease $[18,31,32]$. In the present results, we showed that adenine significantly decreased the activity or concentration of the four oxidative stress biomarkers measured in the renal homogenates. There were no marked differences in the levels of these measurements between the control rats, and rats treated with the two doses of canagliflozin. Concomitant treatment of rats with adenine and canagliflozin significantly mitigated the decrease in the antioxidant levels, although they were not restored to the control levels.

It is known that the transcription factor Nrf2 is the main regulator of antioxidant defenses, and the expression of more than 200 cytoprotective genes [33] and is important for the induction of antioxidant enzymes to respond to oxidative stress. Several therapeutic approaches involve the induction of the Nrf2 antioxidant response to either mitigate or prevent oxidative stress [34]. In this work, renal Nrf2 was detected by an ELISA method. There was a significant rise in the Nrf2 in renal homogenate of rats treated with adenine, probably suggesting that this treatment could trigger adaptive responses that counterbalance the potentially damaging activity of oxygen radicals induced by adenine administration. 


\section{Cellular Physiology Cell Physiol Biochem 2019;52:27-39

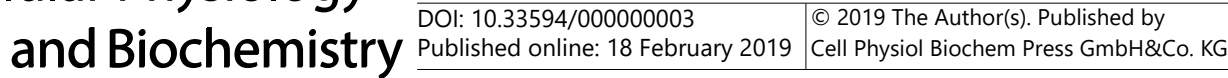 \\ Badreldin et al.: Canagliflozin on Adenine-Induced Chronic Kidney Disease in Rats}

Previous studies have shown that Nrf2 expression is increased in the kidneys and lungs from mice treated with adenine [35].

In the present work, adenine feeding significantly elevated the plasma concentrations of the pro-inflammatory cytokines IL-6, IL-1 $\beta$ and TNF- $\alpha$, an action that was significantly and dose-dependently ameliorated by canagliflozin. This may suggest that the salutary action of canagliflozin on the affected kidneys involves an anti-inflammatory component. This antiinflammatory action of canagliflozin has also been recently shown in vitro and in vivo (mice) through inhibiting intracellular glucose metabolism and promoting autophagy in immune cells [36].

The small protein cystatin $C$ is a relatively novel plasma biomarker that can be used in the diagnosis of CKD in humans and animals, especially in its early stages. It is considered a reliable marker of renal impairment and is less influenced by muscle mass [37]. Adenine treatment in this work caused a highly significant increase in its plasma concentration, an action that has been mitigated by canagliflozin in a dose-dependent fashion.

Clusterin, a secreted glycoprotein is an antiapoptotic protein that can be considered a useful biomarker in acute kidney injury. Similar to our results in this work, we have previously found that clusterin plasma concentration is significantly elevated in adenine-induced CKD [17]. Urinary clusterin has recently been reported to be significantly increased in early and late cases of nephropathy [38].

While this work is being written, Mishima et al. [39] reported that, in mice, canagliflozin exerts intestinal effects that diminishes the concentrations of some uremic toxins such as $p$ cresyl sulfate and IS, probably by influencing the intestinal SGLT1 and altering the composition of the gut microbiota. We have found in this work, and in other previous publications, that adenine significantly increased the plasma concentration of IS [17]. Interestingly, all the rats treated with canagliflozin had no measurable level of IS in their plasma. Concomitant treatment with canagliflozin, at the two doses used, caused a significant and dose-dependent decrease in IS concentration. The reduction in the plasma concentration of this important uremic toxin confirms the usefulness of canagliflozin in the amelioration of the adenineinduced renal impairment. The protein-bound uremic toxin has recently been shown to be involved in the pathogenesis and progression of CKD, particularly renal fibrosis [30], and that injection of IS causes renal fibrosis in mice [40]. The molecular mechanism of this action has been postulated to be through the induction of DNA hypermethylation of the secreted frizzled-related protein 5 , and thereafter the activation of Wnt/ $\beta$-catenin signaling [40]. The levels of other uremic toxins, such as phosphorus, have also been shown in the study to be lowered. The position of phosphorus as a uremic toxin has been discussed by Burke [41].

\section{Conclusion}

The present work has presented experimental evidence that canagliflozin is useful in ameliorating adenine-induced CKD in rats, through reduction of several inflammatory and oxidative stress parameters, and other indices such as uremic toxins, and by antagonizing the increase in the renal content of the transcription factor Nrf2. No overt or significant untoward effects have been noted from the drug treatment. Further studies into the mechanisms of the beneficial effect of this new antidiabetic drug in CKD, and its general suitability to all patients with this disease are warranted.

\section{Acknowledgements}

This work was financially supported by an internal grant from SQU (IG/MED/ PHAR/2017/01). We thank Professor Gerald Blunden for reading the MS. 


\title{
Cellular Physiology Cell Physiol Biochem 2019;52:27-39 \begin{tabular}{l|l|l}
\hline DOI: 10.33594/000000003 & ( 2019 The Author(s). Published by
\end{tabular} \\ Published online: 18 February 2019 Cell Physiol Biochem Press GmbH\&Co. KG \\ Badreldin et al.: Canagliflozin on Adenine-Induced Chronic Kidney Disease in Rats
}

\author{
Disclosure Statement
}

No conflict of interest exists.

\section{References}

1 Koye DN, Magliano DJ, Nelson RG, Pavkov ME: The global epidemiology of diabetes and kidney disease. Adv Chronic Kidney Dis 2018;25:121-132.

2 George C, Mogueo A, Okpechi I, Echouffo-Tcheugui JB, Kengne AP: Chronic kidney disease in low-income to middle-income countries: the case for increased screening. BMJ Glob Health 2017;2:e000256.

3 Gregg LP, Hedayati SS: Management of traditional cardiovascular risk factors in CKD: What are the data? Am J Kidney Dis 2018;72:728-744.

4 Yang HC, Zuo Y, Fogo AB: Models of chronic kidney disease. Drug Discov Today Dis Models 2010;7:13-19.

- 5 Ali BH, Al-Salam S, Al Za'abi M, Waly MI, Ramkumar A, Beegam S, Al-Lawati I, Adham SA, Nemmar A: New model for adenine-induced chronic renal failure in mice, and the effect of gum acacia treatment thereon: comparison with rats. J Pharmacol Toxicol Methods 2013;68:384-393.

- 6 Jia T, Olauson H, Lindberg K, Amin R, Edvardsson K, Lindholm B, Andersson G, Wernerson A, Sabbagh Y, Schiavi S, Larsson TE: A novel model of adenine-induced tubulointerstitial nephropathy in mice. BMC Nephrol 2013;14:116.

- 7 Diwan V, Brown L, Gobe GC: Adenine-induced chronic kidney disease in rats. Nephrology 2018;23:5-11.

- 8 Yokozawa T, Zheng PD, Oura H, Koizumi F: Animal model of adenine-induced chronic renal failure in rats. Nephron 1986;44:230-234.

- 9 Ahmed-Sarwar N, Nagel AK, Leistman S, Heacock K: SGLT-2 Inhibitors: Is there a role in type 1 diabetes mellitus management? Ann Pharmacother 2017;51:791-796.

- 10 Heerspink HJL, Kosiborod M, Inzucchi SE, Cherney DZI: Renoprotective effects of sodium-glucose cotransporter-2 inhibitors. Kidney Int 2018;94:26-39.

- 11 Stavropoulos K, Imprialos K, Stavropoulos N, Bouloukou S, Kerpiniotis G, Dimitriadis K, Tsioufis C, Doumas M: Sodium-glucose cotransporter 2 inhibitors: nephroprotective impact on diabetic kidney disease. Cardiovasc Hematol Disord Drug Targets 2018;18:120-126.

12 Tahara A, Takasu T: Prevention of progression of diabetic nephropathy by the SGLT2 inhibitor ipragliflozin in uninephrectomized type 2 diabetic mice. Eur J Pharmacol 2018;830:68-75.

- 13 Nadkarni GN, Ferrandino R, Chang A, Surapaneni A, Chauhan K, Poojary P, Saha A, Ferket B, Grams ME, Coca SG: Acute kidney injury in patients on SGLT2 Inhibitors: A propensity-matched analysis. Diabetes Care 2017;40:1479-1485.

- 14 Liang Y, Arakawa K, Ueta K, Matsushita Y, Kuriyama C, Martin T, Du F, Liu Y, Xu J, Conway B, Conway J, Polidori D, Ways K, Demarest K: Effect of canagliflozin on renal threshold for glucose, glycemia, and body weight in normal and diabetic animal models. PLoS One 2012;7:e30555.

- 15 Ali BH, Ziada A, Al Husseni I, Beegam S, Al-Ruqaishi B, Nemmar A: Effect of Acacia gum on blood pressure in rats with adenine-induced chronic renal failure. Phytomedicine 2011;18:1176-1180.

- 16 Ali BH, Al Balushi K, Al-Husseini I, Mandel P, Nemmar A, Schupp N, Ribeiro DA: Gum acacia mitigates genetic damage in adenine-induced chronic renal failure in rats. Eur J Clin Invest 2015;45:1221-1227.

- 17 Ali BH, Adham SA, Al Za'abi M, Waly MI, Yasin J, Nemmar A, Schupp N: Ameliorative effect of chrysin on adenine-induced chronic kidney disease in rats. PLoS One 2015;10:e0125285.

18 Ali BH, Al-Salam S, Al Suleimani Y, Al Kalbani J, Al Bahlani S, Ashique M, Manoj P, Al Dhahli B, Al Abri N, Naser HT, Yasin J, Nemmar A, Al Za'abi M, Hartmann C, Schupp N: Curcumin ameliorates kidney function and oxidative stress in experimental chronic kidney disease. Basic Clin Pharmacol Toxicol 2018;122:65-73.

19 Servais A, Meas-Yedid V, Buchler M, Morelon E, Olivo-Marin JC, Thervet E: Quantification of interstitial fibrosis by image analysis on routine renal biopsy 1 year after transplantation in patients managed by C2 monitoring of cyclosporine microemulsion. Transplant Proc 2007;39:2560-2562.

20 Al Za'abi M, Al Salam S, Al Suleimani Y, Manoj P, Nemmar A, Ali BH: Gum acacia improves renal function and ameliorates systemic inflammation, oxidative and nitrosative stress in streptozotocin-induced diabetes in rats with adenine-induced chronic kidney disease. Cell Physiol Biochem 2018;45:2293-2304. 


\section{Cellular Physiology Cell Physiol Biochem 2019;52:27-39 \begin{tabular}{c|l} 
DOI: 10.33594/000000003 & (c) 2019 The Author(s). Published by
\end{tabular} and Biochemistry Published online: 18 February 2019 Cell Physiol Biochem Press GmbH\&Co. KG \\ Badreldin et al.: Canagliflozin on Adenine-Induced Chronic Kidney Disease in Rats}

- 21 Schneider CA, Rasband WS, Eliceiri KW: NIH Image to ImageJ: 25 years of image analysis. Nat Methods 2012;9:671-675.

- 22 Devineni D, Polidori D: Clinical pharmacokinetic, pharmacodynamics, and drug-drug interaction profile of canagliflozin, a sodium-glucose co-transporter 2 inhibitor. Clin Pharmacokinet 2015;54:1027-1041.

23 Claramunt D, Gil-Peña H, Fuente R, García-López E, Loredo V, Hernández-Frías O, Ordoñez FA, RodríguezSuárez J, Santos F: Chronic kidney disease induced by adenine: a suitable model of growth retardation in uremia. Am J Physiol Renal Physiol 2015;309:F57-62.

24 Saucedo AL, Perales-Quintana MM, Paniagua-Vega D, Sanchez-Martinez C, Cordero-Perez P, Minsky NW: Chronic kidney disease and the search for new biomarkers for early diagnosis. Curr Med Chem 2018;25:3719-3747.

25 Lopez-Giacoman S, Madero M: Biomarkers in chronic kidney disease, from kidney function to kidney damage. World J Nephrol 2015;4:57-73.

26 Pedraza-Chaverri J, Sánchez-Lozada LG, Osorio-Alonso H, Tapia E, Scholze A: New pathogenic concepts and therapeutic approaches to oxidative stress in chronic kidney disease. Oxid Med Cell Longev 2016;2016:6043601.

27 Tabriziani H, Lipkowitz MS, Vuong N: Chronic kidney disease, kidney transplantation and oxidative stress: a new look to successful kidney transplantation. Clin Kidney J 2018;11:130-135.

- 28 Alicic RZ, Johnson EJ, Tuttle KR: Inflammatory mechanisms as new biomarkers and therapeutic targets for diabetic kidney disease. Adv Chronic Kidney Dis 2018;25:181-191.

- 29 Askari H, Seifi B, Kadkhodaee M, Sanadgol N, Elshiekh M, Ranjbaran M, Ahghari P: Protective effects of hydrogen sulfide on chronic kidney disease by reducing oxidative stress, inflammation and apoptosis. EXCELI J 2018;17:14-23.

- 30 Lv W, Booz GW, Fan F, Wang Y, Roman RJ: Oxidative stress and renal fibrosis: recent insights for the development of novel therapeutic strategies. Front Physiol 2018;9:105-115.

31 Jing W, Vaziri ND, Nunes A, Suematsu Y, Farzaneh T, Khazaeli M, Moradi H: LCZ696 (Sacubitril/valsartan) ameliorates oxidative stress, inflammation, fibrosis and improves renal function beyond angiotensin receptor blockade in CKD. Am J Transl Res 2017;9:5473-5484.

32 Liguori I, Russo G, Curcio F, Bulli G, Aran L, Della-Morte D, Gargiulo G, Testa G, Cacciatore F, Bonaduce D, Abete P: Oxidative stress, aging, and diseases. Clin Interv Aging 2018;13:757-772.

33 Nguyen T, Nioi P, Pickett CB: The Nrf2-antioxidant response element signaling pathway and its activation by oxidative stress. J Biol Chem 2009;284:13291-13295.

34 Barančík M, Grešová L, Barteková M, Dovinová I: Nrf2 as a key player of redox regulation in cardiovascular diseases. Physiol Res 2016;65:S1-S10.

35 Nemmar A, Karaca T, Beegam S, Yuvaraju P, Yasin J, Ali BH: Lung oxidative stress, DNA damage, apoptosis, and fibrosis in adenine-induced chronic kidney disease in mice. Front Physiol 2017;8:896-905.

- 36 Xu C, Wang W, Zhong J, Lei F, Xu N, Zhang Y, Xie W: Canagliflozin exerts anti-inflammatory effects by inhibiting intracellular glucose metabolism and promoting autophagy in immune cells. Biochem Pharmacol 2018;152:45-59.

- 37 DSa J, Shetty S, Bhandary RR, Rao AV: Association between serum Cystatin C and creatinine in chronic kidney disease subjects attending a tertiary health carecentre. J Clin Diagn Res 2017;11:BC09-BC12.

- 38 Martynova EV, Maksudova AN, Shakirova VG, Abdulkhakov SR, Khaertynova IM, Anokhin VA, Ivanova VV, Abiola IM, Garanina EE, Tazetdinova LG, Valiullina AH, Khaiboullina SF: Urinary clusterin is upregulated in nephropathic epidemic. Dis Markers 2018;2018:8658507.

39 Mishima E, Fukuda S, Kanemitsu Y, Saigusa D, Mukawa C, Asaji K, Matsumoto Y, Tsukamoto H, Tachikawa T, Tsukimi T, Fukuda NN, Ho HJ, Kikuchi K, Suzuki C, Nanto F, Suzuki T, Ito S, Soga T, Tomioka Y, Abe T: Canagliflozin reduces plasma uremic toxins and alters the intestinal microbiota composition in achronic kidney disease mouse model. Am J Physiol Renal Physiol 2018;315:F824-F833.

40 Yu Y, Guan X, Nie L, Liu Y, He T, Xiong J, Xu X, Li Y, Yang K, Wang Y, Huang Y, Feng B, Zhang J, Zhao J: DNA hypermethylation of sFRP5 contributes to indoxyl sulfate-induced renal fibrosis. J Mol Med 2017;95:601613.

- 41 Burke SK: Phosphate is a uremic toxin. J Ren Nutr 2008;18:27-32. 